\title{
Correspondence
}

\section{Comment on: Growth characteristics in children with congenital adrenal hyperplasia}

\author{
To the Editor
}

I have 2 comments on the distinguished study by Alzanbagi et al on the growth characteristics in Saudi children with congenital adrenal hyperplasia $(\mathrm{CAH}) .{ }^{1}$

First, over the period of 5 years (January 2012 and January 2017), the authors measured the growth parameters of weight and height in $\mathrm{CAH}$ patients aged between 0 and 18 years. Alzanbagi et al interpreted body mass indices (BMI) of the studied patients using the World Health Organization (WHO) BMI percentile charts for age and gender. They found a significant effect of $\mathrm{CAH}$ on height, weight, and BMI. ${ }^{1}$ They addressed that underweight and obesity were reported in 19.1\% and $17.6 \%$ of the studied population, while short stature and normal height were recorded in $25.7 \%$ and $74.3 \%{ }^{1}$ Apart from many limitations addressed by the authors, that might cast some suspicions on the accuracy of the study results, I presume that the following limitation might be additionally contributory. It is explicit that in the pediatric clinical setting, there are many growth charts employed to estimate different anthropometric indices, namely Center for Disease Control (CDC) charts, WHO charts, and countryspecific charts. Evaluation of these charts suggested that country-specific charts might describe the growth of children more precisely. ${ }^{2}$ In certain populations, the clinical implementation of national charts disclosed unique patterns of BMI percentiles compared to CDC and WHO charts. These national charts were considered useful as a reference for monitoring the growth changes over time and for comparing various regions. ${ }^{3}$ To my knowledge, L, $\mathrm{M}$, and $S$ parameters as well as Z scores were calculated for weight, height, and BMI for Saudi preschool-age children, ${ }^{4}$ school-age children, and adolescents. ${ }^{5}$ They have been launched in 2016 for more accurate assessment of growth and nutrition in the clinical field and researches. I wonder why Alzanbagi et al ${ }^{1}$ referred to WHO charts instead of the national Saudi growth charts to estimate BMI percentiles of the studied cohort. I presume that if they employed national BMI charts, different results might be obtained.
Second, in view of the high rate culturally-based consanguineous marriage $(29.7 \%)$ in the Saudi general population $^{6}$ and high nationwide incidence of $\mathrm{CAH}$ $(1: 7908),{ }^{7}$ which is so far one of the greatest reported incidence worldwide, marked inbreeding cases of $\mathrm{CAH}$ are expected to be faced in the foreseeable time. Meticulous monitoring of the growth of these $\mathrm{CAH}$ patients represents a major step to be followed. Hence, establishment of Saudi-specific growth curves for $\mathrm{CAH}$ patients similar to that constructed in certain populations, ${ }^{8}$ is suggested.

\section{Mahmood D. Al-Mendalawi Department of Paediatrics Al-Kindy College of Medicine University of Baghdad Baghdad, Iraq}

\section{Reply from the Author}

No reply was received from the Author.

\section{References}

1. Alzanbagi MA, Milyani AA, AlAgha AE. Growth characteristics in children with congenital adrenal hyperplasia. Saudi Med J 2018; 39: 674-678.

2. Ziegler EE, Nelson SE. The WHO growth standards: strengths and limitations. Curr Opin Clin Nutr Metab Care 2012; 15 : 298-302.

3. Ma J, Wang Z, Song Y, Hu P, Zhang B. BMI percentile curves for Chinese children aged 7-18 years, in comparison with the WHO and the US centers for disease control and prevention references. Public Health Nutr 2010; 13: 1990-1996.

4. Shaik SA, El Mouzan MI, AlSalloum AA, AlHerbish AS. Growth reference for Saudi preschool children: LMS parameters and percentiles. Ann Saudi Med 2016; 36: 2-6.

5. El Mouzan MI, Al Salloum AA, Alqurashi MM, Al Herbish AS, Al Omar A. The LMS and Z scale growth reference for Saudi school-age children and adolescents. Saudi J Gastroenterol 2016; 22: 331-336.

6. Warsy AS, Al Jaser MH, Albdass A, Al Daihan S, Alanazi M. Is consanguinity prevalence decreasing in Saudis? A study in two generations. Afr Health Sci 2014; 14: 314-321.

7. Alfadhel M, Al Othaim A, Al Saif S, Al Mutairi F, Alsayed M, Rahbeeni Z, et al. Expanded newborn screening program in Saudi Arabia: Incidence of screened disorders. J Paediatr Child Health 2017; 53: 585-591.

8. Bretones P, Riche B, Pichot E, David M, Roy P, Tardy V, et al. Growth curves for congenital adrenal hyperplasia from a national retrospective cohort. J Pediatr Endocrinol Metab 2016; 29: 1379-1388 